\title{
Analysis on the Book Binding Design problem in the New Period
}

\author{
Zhuo Yang \\ Media Art College, Chongqing College of Electronic Engineering, Chongqing, 401331, China \\ zhuoyang@163.com
}

Keywords: Book binding; Design; Medium

\begin{abstract}
The development of book binding design has been accompanied by the progress of the human civilization and culture, the application of new technology, new material has become the important characteristic of the book design in today's society. In the modern sense of book binding design, to a large extent it depends on the improvement of the social productivity and the progress of science and technology. The development of the book binding design, as it were, with the development of material civilization is synchronous, when we entered the 21st century, the knowledge economy has been coming on the earth, in the face of the rapid development of science and technology in today's world and the status quo of China's economic take-off, the book designer is shouldering the development for the society to create knowledge and cultural wealth of historical mission. This article mainly discusses the book binding design problem in the new period.
\end{abstract}

\section{Introduction}

The books as the main carrier of language, is the human thought, spreading knowledge, accumulation of culture medium of material. Shakespeare once said: "books are the summary of human knowledge, is the nourishment of the world". It is because the book is bearing the weight of the history of human civilization and the crystallization of the wisdom of, at the same time, with the rapid development of science and technology and publishing industry, to make the art form of book decoration design more and more get the attention of people. In the process of the change of the binding art form, reflected the progress of the society, the development of culture, influenced people's ideas and aesthetic consciousness at the same time, also makes the book binding design level has improved greatly. Now say a good book, in addition to its content, also look at its formal beauty, no good binding form, not the interest of others, naturally. A good book should be in a graceful covers, illustrations, choreography, word to attract readers, increase the reader's interest and comfort, intuitively the vision has desire, let readers make readers in to buy a book from the materials, choreography, beautify feel enjoyable, fondle admiringly, this to reach the purpose of the book, the following I mainly talk about some views of book design.

\section{The characteristics of the book binding design}

The book binding design or books design, including the cover, the cover page, preface, text, illustrations, back cover, jacket size, paper, selection, and so on a series of design, as well as to the format design, printing, binding method choice. Book was originally designed to easy to read, easy to save, easy to carry, but today, it has already moved beyond the basic sense of the role, but by graphics, text, color and other visual elements to convey the designer concept and spirit connotation, convey the books information. Book design is design in modelling, the design language do word can not do, so we should follow certain principles, namely the need to clear the primary and secondary, don't be a presumptuous guest usurps the host's role, and it is certain to should have creativity, beyond the traditional form, simple line. Good book design can not only promote the communication of information, and building the bridge the reader and the author's ideas. Therefore, the book binding design in addition to reflect the original design, the characteristics of another important feature is to accurately convey the center of the books content and ideas, in order to achieve the unity of content 
and form. Through the choice of different materials, different technology, use, make the ideas of the books and the art of book binding design highly unified, books content and form, the thought and art become coordinated process, practical and aesthetic of art as a whole.

\section{The traditional design concept and binding books}

\section{The size selection}

The books known as the size, the size of the layout in the paper of the basic computing unit, each all paper cutting and folding as many folios chamberlain is called. As a whole piece of paper folded in half once get xiao zhang, known as the "split", folded in half again as "4" and so on, can also get 8, 16, 32, 64 open folios. At present, the domestic production of common size paper mainly has the following three types: (1) $787 \mathrm{~mm} \times 1092 \mathrm{~mm}$ this is the current book publishing the main dimensions of the printing paper. As we are now common 32 book and 16 folio edition book is using the specifications of the paper. (2) it is $850 \mathrm{~mm} \times 850 \mathrm{~mm}$, in order to meet the need of large size book printing and production, such as many current textbooks used 32 books, is to use this paper. $880 \mathrm{~mm}$ $\mathrm{x} 1230 \mathrm{~mm}$ (3) this is a kind of international comparison of general specification, the size of paper size is bigger than the size of the other same size, the printing paper utilization rate is higher, when the form is beautiful and easy.

The current in the practice of the book publishing, typically choose different size according to the content and quality of books. Such as the poetry usually adopt more narrow little; Theory of science and technology books generally adopted the 32 and 16 folio edition; Children's books with close to the square of small size, such as 24 size; Pocket dictionary usually use size 42 open, 48 or 64; Pictorial usually adopt approximate square size, and so on.

\section{The books design}

Both advertising and protection of the design for books, it includes jacket cover, (and the spine and le mouth), covers, belts, plug, favorites or bookmarks, book (brush or brush color), ShuKou (ladder label or ShuKou painting), and other design. General paperback cover is printed with the title, name of the author, the translator's name and press, and matches by the proper design, book, display book content plays a beautification and protect the book core role. Kisses on the back cover of sichuan editor, cover design, unified with kisses and pricing, the number of intermediate configuration certain patterns or words with a nature of advertising. Spine refers to the spine, coupling cover and back cover general bearing the title, $\mathrm{CeCi}$ (volume, set, volumes), the author, the translator's name and press, its main function is in the book shelf, easy to find. At present, the domestic book, most of the paperback book, otherwise a small amount of hardcover book. In terms of exterior design, hardcover and paperback books, mainly in the cover and back cover, jacket do have, that is wrapped in hardcover book cover and back cover the protection of the outer surface of paper, which is also called outer cover or coating. Some hardcover books, equipped with HanTao, a series of loading of cardboard boxes, its role is to protect the books.

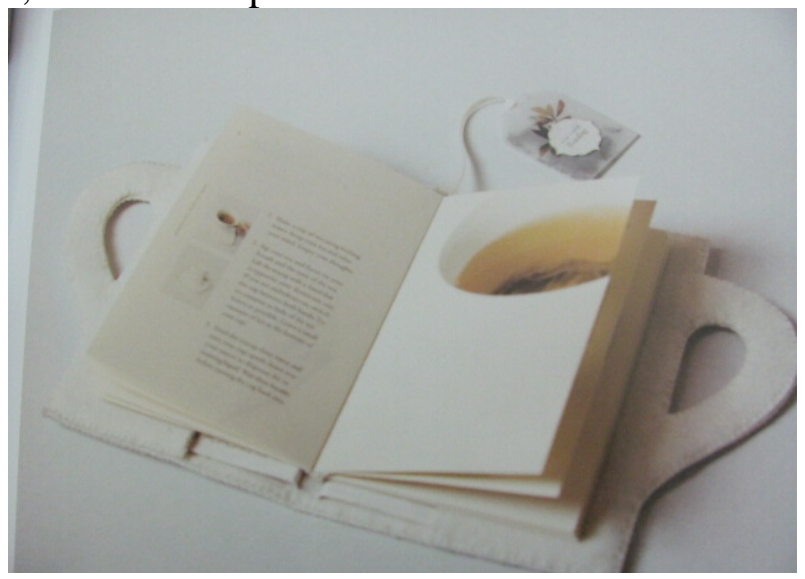

Figure 1 


\section{The book block format}

The book core graphic format arrangement is the core of the book binding design of main body, including: type area and around four mouth (barns, anchor, incision, book), the font, font size, word spacing and row spacing, columns, as well as the title, text, the text first, annotation, the top of a page, or the design of the raphe, page number, etc; Also includes preface, foreword, directory, or diagram, postscript or postscript, index, bibliography, chronology, etc in the form of a design, as well as pictures and illustrations of the format layout and structure, etc. , usually have a unified format specification requirements, individual book some creative freedom, but the pace is not large.

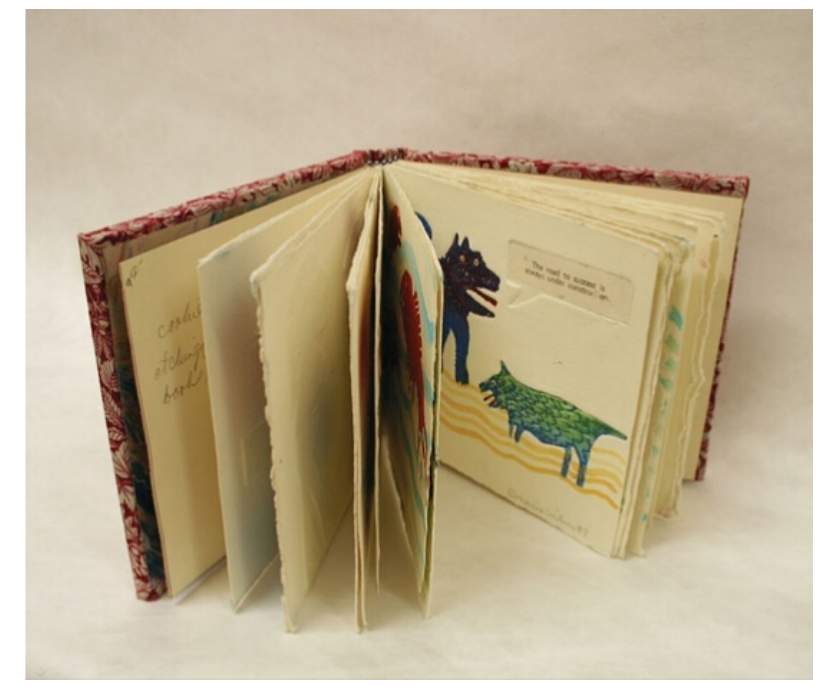

Figure 2

\section{The problems of the book binding design}

\section{The select material single}

Because of the function orientation of a single, material to choose his own ways, followed by a lot of limitations. At present, although there are few books using silk, cloth, leather, wood, chemical fiber, plastic, etc. To print, but most of the books or the traditional paper-based materials.

\section{The single appearance style}

Because only the book is regarded as a learning tool for people to read, rather than regard it as a work of art to produce, it will determine the appearance of books in modelling is very tedious. Look at today's book market, you can see, the book, at present, basically all size is differ, or thick or thin brick.

\section{Inflexible}

Although individual books carefully edited, illustrated, but generally speaking, the choreography is generally books edition, inflexible, basically all is neat rectangle section, closely printed on some of the big or small black font. Even if a few part of the color printing books, some are colorful, its layout form also pretty dull.

\section{The book binding design innovation strategy in the new period}

The cultural connotation of book binding design requirement stylist when the design is not only to highlight the book itself is the content of the manuscript, more clever use of book design artistic appeal, for readers to build rich aesthetic space, and it can better meet people's spiritual and material requirements. Book design from the person's psychology, living habits and other factors to consider, in accordance with the principle of a kind of aesthetic law and to the material form of transformation activities, is a kind of creative thinking to representational, improve people's lives artistic aesthetic expression, aesthetic and practical design reflects the highly unified, form and function of complement each other, humane connotation, establish the principles of modern design aesthetics 
from the concept of the essential characteristics of human being. The quality of book binding design is not only related to the grade of the book itself, the press of the image, but also directly affects the sales of books. In the book topic selection, the process of planning, design, production, designers and press according to the different levels of readers' requirements and aesthetic temperament and interest, make accurate positioning, book binding design to achieve maximum economic benefits.

\section{Conclusions}

The book binding design art is as with other arts, which reflects a certain era of the economic base, and has the characteristics of era. Entering the 21st century, all kinds of science and technology are in the rapid development, the economic level also rises rapidly; the book binding design also meets with the challenges of the new technology, the new material and printing craft and the new media. How can we rushed out of the challenge, and design out of books with time characteristics, it is the problems that the general designer are thinking about. The book binding designer must have a variety of comprehensive skills, not only have profound knowledge, also have the consummate skill, which it can be used all kinds of materials and technologies to the artistic creation, and to make better book binding design work.

\section{References}

[1] Yoshio Okumura. Developing a Spectral and Colorimetric Database of Artist Paint Materials. 2012(10)

[2] Dibakar Raj Pant. Determination of Optical Characteristics of Material for Computer Colorant Analysis. 2013(08)

[3] P. MASTERSON. Book Design and Production. 2012(12)

[4] Robinson. A summary of Reflectance Equations for duplication of the Kubelka-Munk Theory topical Properties of Paper. TAPPI Journal. 2013(08)

[5] J. A. Cogon. Linear and quadratic optimization algorithms for computer color matching. Color Research and Application.2012(06)

[6] De LUCI A Maurizio, BUONOPANE Massimo. Color Prediction in Textile Application. Optical Metrologyin Production Engineering. 2013(11)

[7] Pesal Koirala,, Markku Hauta-Kasari,Birgitta Martinkauppi,Jouni Hiltunen. Color Mixing and Color Separation of Pigments with Concentration Prediction. Color Research and Application. 2012(06) 